\title{
Studies on Maleic Anhydride Grafted Reclaimed Rubber/Acrylonitrile Butadiene Rubber Blends
}

\author{
P.A. Nelson and S.K.N. Kutty* \\ Depariment of Polymer Science and Rubber Technology, Cochin University of \\ Science and Technology, Cochin 682022, India. Fax: -91-484-577747 \\ E mail: sunil@cusat.ac.in
}

Received: 29 October 2002 Accepted: 30 January 2003

\begin{abstract}
Blends of Acrylonitrile rubber with Maleic anhydride grafted Whole Tyre Reclaim WTR (MA-g-WTR) have been prepared and the cure and mechanical properties have been studied with respect to reclaim content. Control compounds containing unmodified WTR were also prepared for comparison. Grafting was confirmed by IR studies. Blends containing grafted WTR showed higher minimum torque and (max-min) torque. They also showed longer cure time, scorch time and lower cure rate. Grafting of the WTR with maleic anhydride also resulted in the improved tensile strength, abrasion resistance, compression set and resilience. However, the heat build up under dynamic loading was marginally higher for the blends containing grafted reclaimed rubber.
\end{abstract}

\section{INTRODUCTION}

Reclaimed rubber, prepared from scrap rubber has been used as substitution for virgin rubber in many rubber compounds ${ }^{(1-13)}$. The properties of such blends depend critically on the compatibility of the component matrices. Whole tyre reclaim (WTR), a popular form of reclaimed rubber prepared from used and scrap tyres, is inherently non-polar and has been used to prepare blends with non-polar rubber such as NR, SBR and BR ${ }^{(14-16)}$. Kim and Burford studied the utilization of waste tyres in polar and non polar rubbers ${ }^{(17)}$.

\footnotetext{
"To whom all correspondence should bè sent
} 
However, to be used in blends with polar rubbers such as NBR, the WTR has to be made more compatible by grafting polar groups on to it. Maleic anhydride is often used to functionalise elastomers. Farmer and Wheeler patented the method of modifying rubber with the maleic anhydride. Maleic anhydride is grafted on the double bond of the rubber hydrocarbon. Functionalization is usually accelerated in presence of organic peroxide like dicumylperoxide (DCP). Maleic anhydride readily reacts with polymeric double bonds and free radicals by an ENE reactions ${ }^{(18-20)}$. In this work we report the results of our study on the grafting of maleic anhydride onto WTR and properties of its blends with NBR.

\section{EXPERIMENTAL}

\section{Materials used}

Nitrile rubber (NBR) N553 grade used in this study with Mooney viscosity $\left[\mathrm{ML}(1+4)\right.$ at $\left.100^{\circ} \mathrm{C}\right] 45$ and an acrylonitrile content of $33 \%$, was supplied by Apar Polymers Ltd., India. Reclaimed rubber (WTR) was obtained from Kerala Rubber and Reclaims, Mamala, Kerala, India. The characteristics of WTR used are given in the Table 1. Dicumylperoxide (DCP), zinc oxide, sulphur, mercaptobenzothiazoledisulphide (MBTS), tetramethylthiuramdisulphide (TMTD) and stearic acid were obtained from Sameera Enterprises Kottayam. Antioxidant 4020 [N (1,3, dimethyl - butyl) N' phenyl p- phenylenediamine ] was obtained from Bayer India Ltd. Maleic anhydride was supplied by Merck India Ltd.

\begin{tabular}{|c|c|}
\hline Table $\mathbf{1}$ Characteristics of reclaimed rubber \\
\hline Property & Value \\
\hline Acetone extract (\%) & 15 \\
\hline Carbon black (\%) & 30 \\
\hline Gel content (\%) & 68 \\
\hline Mooney Viscosity & 24 \\
\hline Particle size & 30 mesh \\
\hline
\end{tabular}


Studies on Maleic Anhudride Grafted Reclaimed Rubber/Acrulonitrile Butadiene Rubber Blends

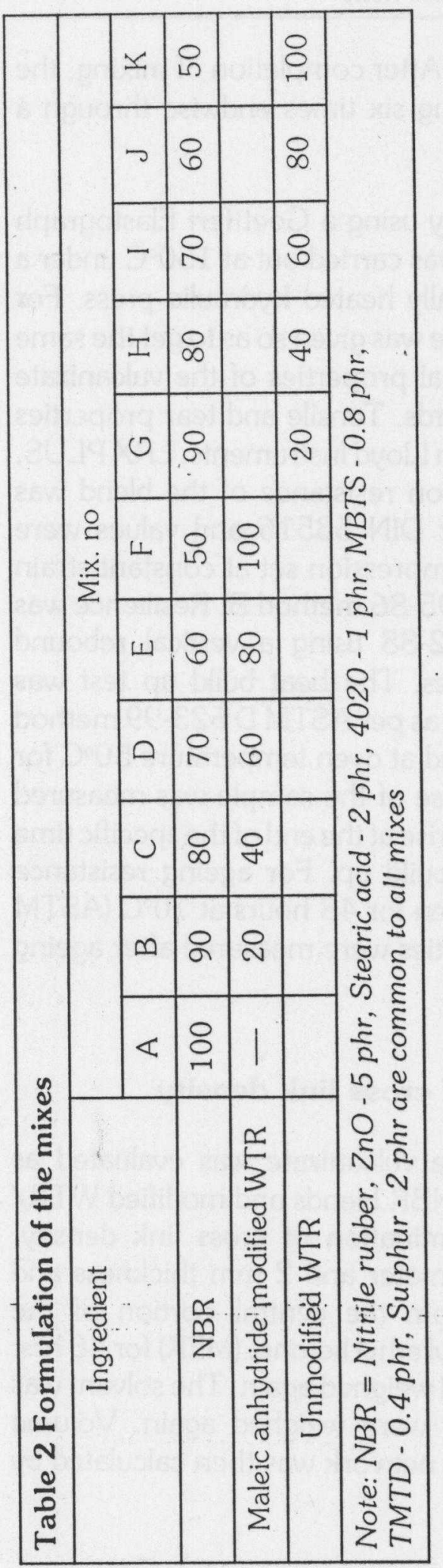

Grafting of maleic anhydride on reclaimed rubber

A Brabender Plasticorder (torque Rheometer) model PS $3 S$ equipped with roller type rotors, having a capacity of $40 \mathrm{~g}$., was used for grafting maleic anhydride on reclaimed rubber.

$40 \mathrm{gm}$ of reclaimed rubber was mixed with $2 \mathrm{gm}$ of maleic anhydride in the presence of $1 \mathrm{gm}$ of dicumylperoxide (DCP) at a temperature of $150^{\circ} \mathrm{C}$ in Brabender Plasticorder at $30 \mathrm{rpm}$ speed for 3 mins. Grafting reaction was completed within 3 mins. At the end of 3 mins of mixing, the samples were taken out and homogenized on a two-roll mill. A blank was prepared with out the addition of maleic anhydride and DCP. Then both the samples were extracted with toluene for $48 \mathrm{hrs}$ continuously. The solvent in the extract was removed by evaporation in a vacuums pump. The sample was then extracted with acetone to remove impurities and finally dried to remove the solvent. After these processes FTIR spectrum of the modified and unmodified samples were taken on a Nicolet AVATAR 360 ESP FTIR Spectrometer.

\section{Preparation of blends}

Formulations of the mixes are given in Table 2.

The blends were prepared on a laboratory size two roll mill $(150 \mathrm{x}$ 
$330 \mathrm{~mm}$ ) as per ASTM D 3182(1989). After completion of mixing, the compound was homogenized by passing six times endwise through a tight nip and finally sheeted out.

Cure characteristics were determined by using a Goettfert Elastograph model 67.85 at $150^{\circ} \mathrm{C}$. Vulcanization was carried out at $150^{\circ} \mathrm{C}$ under a pressure of $180 \mathrm{~kg} / \mathrm{cm}^{2}$ in an electrically heated hydraulic press. For thicker samples, sufficient extra cure time was given so as to get the same extent of cure. The different mechanical properties of the vulcanizate were tested according to ASTM standards. Tensile and tear properties were measured using a tensile tester from Lloyd Instruments, LRXPLUS, according to ASTM D 412.The abrasion resistance of the blend was measured using a DIN abrader as per DIN 53516 and values were expressed as volume loss per hour. Compression set at constant strain was measured according to ASTM D 395-86 method B. Resilience was measured according to ASTM D2832-88 using a vertical rebound Resilience tester from Modex Industries. The heat build up test was carried out using a Goodrich Flexometer as per ASTM D 623-99 method A. The test samples were preconditioned at oven temperature $50^{\circ} \mathrm{C}$ for 20 mins. The heat developed at the base of the sample was measured using a thermocouple. The temperature rise at the end of the specific time interval ( 20 mins) was taken as heat build up. For ageing resistance studies, samples were aged in an air oven for 48 hours at $70^{\circ} \mathrm{C}$ (ASTM D 573-88). The tensile and tear properties were measured after ageing in an air oven.

\section{Determination of concentration of cross link density}

The chemical cross-link density of the vulcanizate was evaluated as follows. Samples of unmodified WTR/NBR blends and modified WTR/ NBR blends were used for the determination of cross link density. Samples of approximately $10 \mathrm{~mm}$ diameter and $2 \mathrm{~mm}$ thickness and $0.2 \mathrm{gm}$ weight were punched out from the central portion of the vulcanizate and allowed to swell in Methyl ethyl ketone. (MEK) for $48 \mathrm{hrs}$. The swollen samples were taken out and weighed again. The solvent was removed in vacuum and the samples were weighed again. Volume fraction of the rubber $\mathrm{Vr}$ in the swollen network was then calculated by following equation ${ }^{(21-22)}$

$$
V r=\frac{(D-F T) \rho_{r}^{-1}}{(D-F T) \rho_{r}^{-1}+A_{0} \rho_{s}^{-1}}
$$


Studies on Maleic Anhydride Grafted Reclaimed Rubber/Acrylonitrile Butadiene Rubber Blends

- Where T is the weight of test-specimen, $D$ is the weight of deswollen test specimen, $F$ is the weight of fraction of insoluble components. $A_{0}$ weight of absorbed solvent corrected for the swelling increment. Density of the rubber $\rho_{\mathrm{r}}$ was $1.018 \mathrm{~g} / \mathrm{cm}^{3}$ and $\rho_{\mathrm{s}}$ was the density of the solvent MEK, it was $0.804 \mathrm{~g} / \mathrm{cm}^{3}$.

Knowing the value of $\mathrm{Vr}$, the total chemical cross link density was calculated using Flory-Rehner equation ${ }^{(23-24)}$.

$$
-\ln (1-V r)+V r+\chi V_{r}^{2}=\frac{\rho_{r} V_{s}(V r)^{1 / 3}}{M c}
$$

where $V_{s}$ is the molar volume of the solvent $\chi$ is the parameter characteristic of the interaction between rubber and solvent $\mathrm{Mc}$ is the number average molecular weight of rubber chains between the cross links. The value of the parameter $\chi$ taken for NBR -MEK system was $0.21^{(25)}$.

\section{RESULTS AND DISCUSSION}

\section{Maleic anhydride grafting}

Figure 1 shows FTIR spectrum of modified and unmodified reclaimed rubber. An additional peak appearing at $1783 \mathrm{~cm}^{-1}$ corresponding to carbonyl vibration in the case of modified WTR indicates that reclaim has been grafted.

\section{Cure characteristics}

Figure 2 shows the variation of minimum torque of the blends containing modified and unmodified WTR. The blends with the modified WTR shows consistently higher torque values indicating a more viscous matrix. This may be resulting from improved polar interaction of NBR with the grafted WTR. However, with increasing loading of maleic anhydride grafted WTR (MA-g WTR), the minimum torque value decreases as in the case of blends with unmodified WTR. The reclaim rubber contains 15\% of plasticizer in addition to rubber hydrocarbon and filler (Table 1). Increasing the proportion of WTR also increases plasticizer content of the blends, which results in the net reduction of the initial viscosity. 
Figure 1 FTIR spectrum of modified and unmodified reclaimed rubber
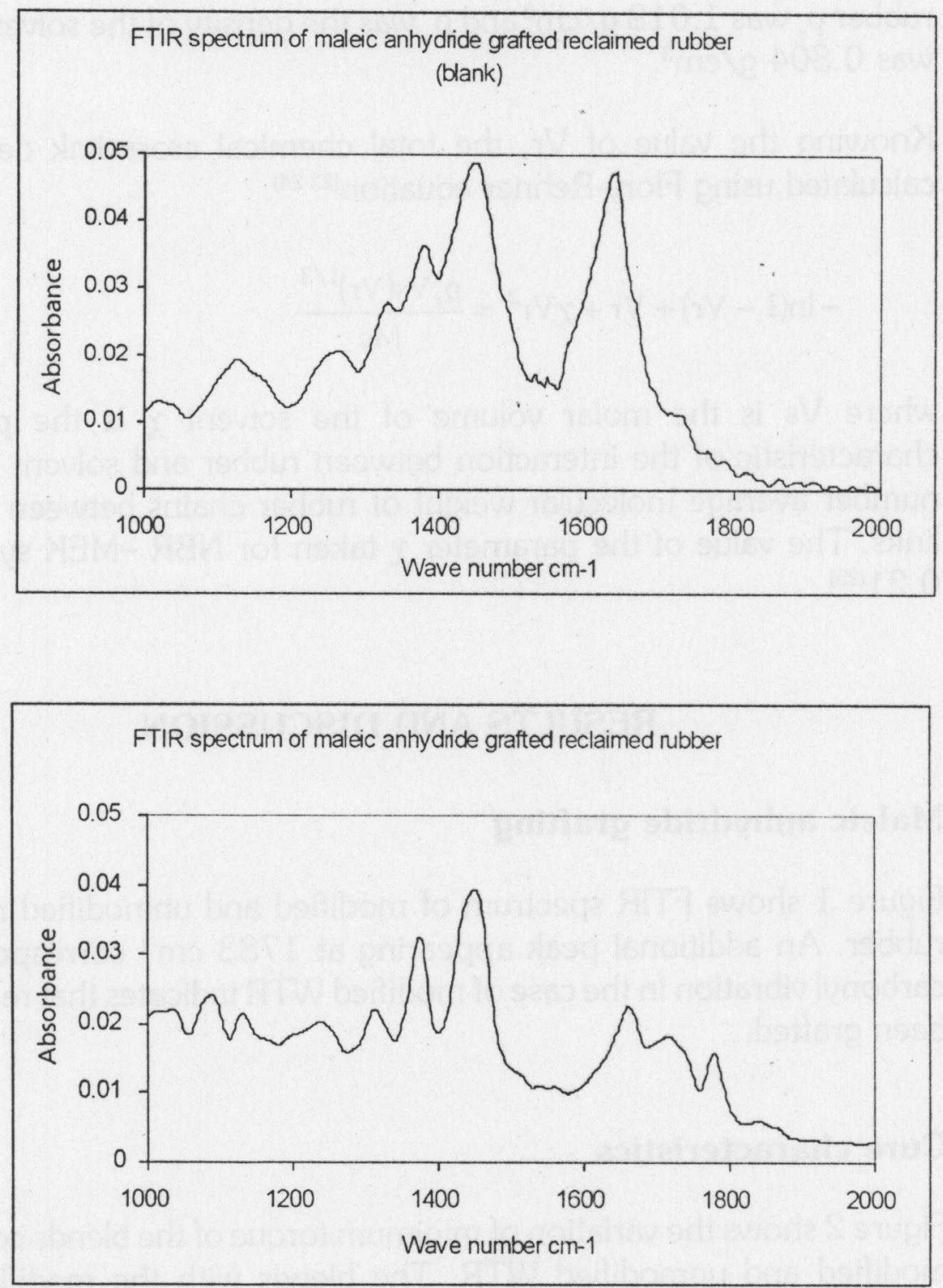

Figure 3 shows the variation of (maximum - minimum) torque $(\Delta T)$. In all the cases the $(\Delta T)$ of the blends containing modified WTR is higher than that of the unmodified blends, indicating a relatively more restrained matrix resulting from the combined effect of higher interaction between blend components and higher levels of cross links formed. With increasing reclaim content in the blends, the $(\Delta \mathrm{T})$ is found to be gradually decreased, 


\section{Figure 2 Comparison of minimum torque with reclaim loading}

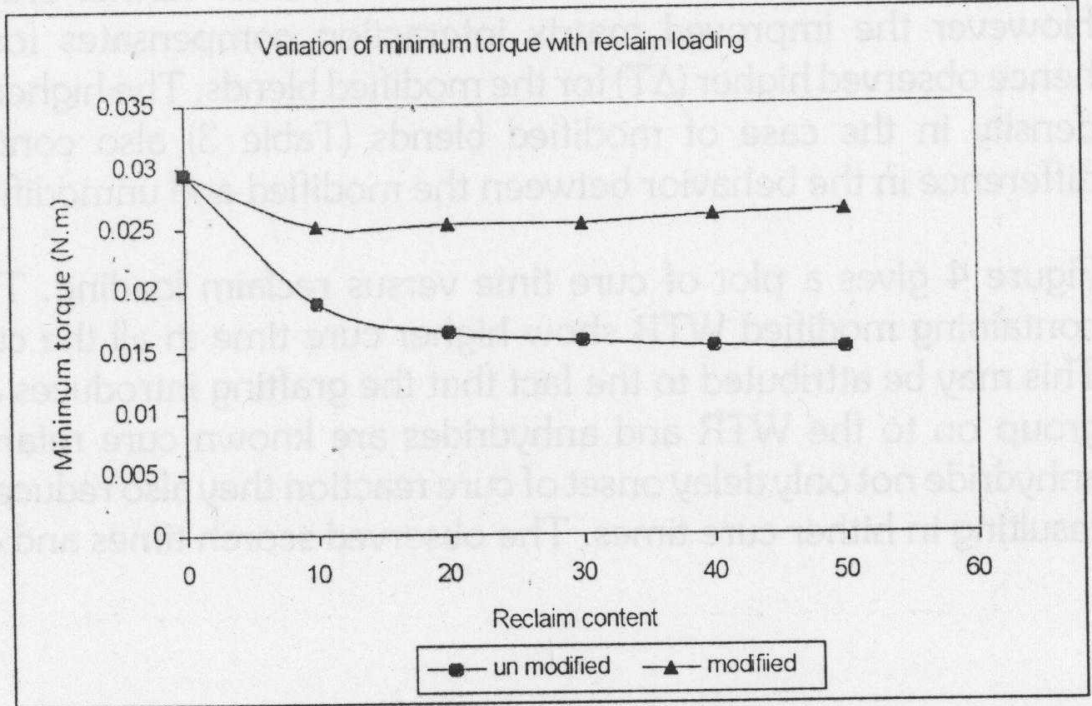

Figure 3 Comparison of maximum- minimum torque with reclaim loading

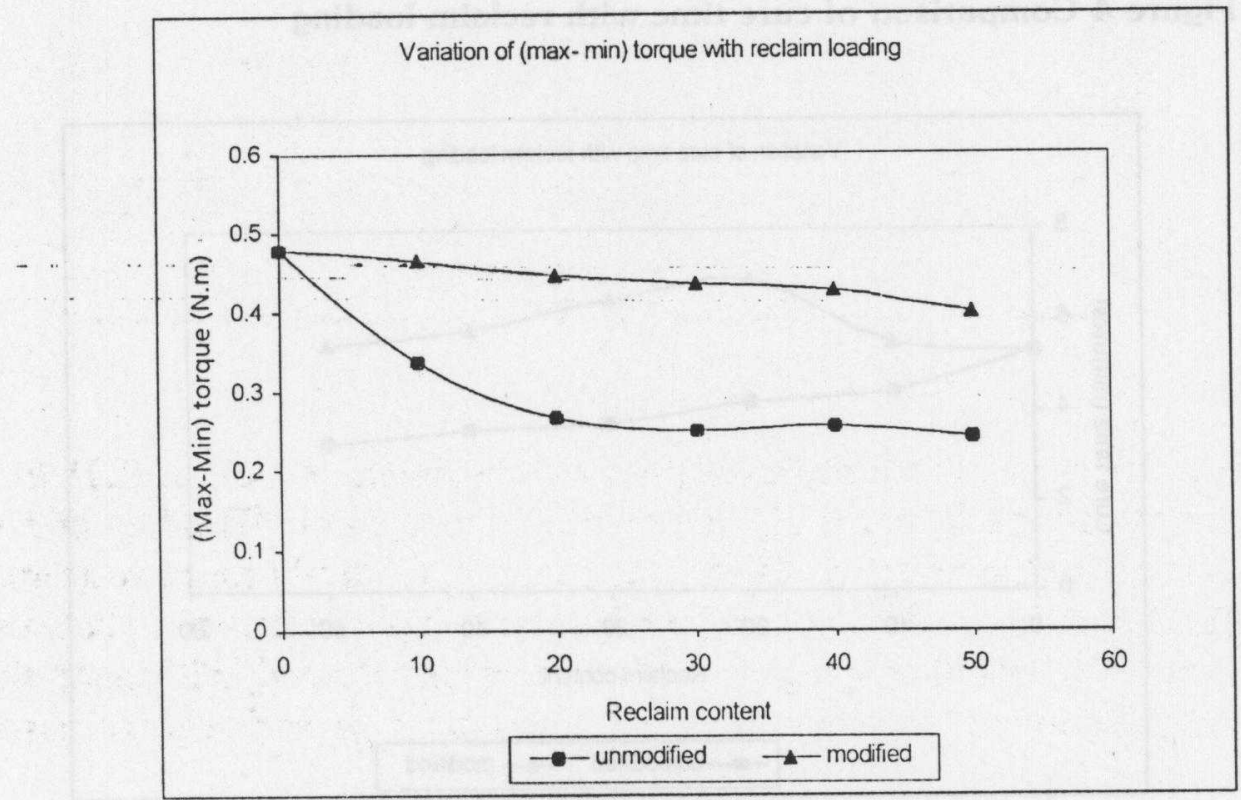


the effect being less significant in the case of MA-g-WTR blends. The lower level of cross links at higher reclaim loading may be attributed to the fact that the reclaim is already partially cross linked matrix and hence there is relatively less reaction sites available for further cross linking. However the improved matrix interaction compensates for this and hence observed higher $(\Delta T)$ for the modified blends. The higher cross link density in the case of modified blends (Table 3) also contributes to difference in the behavior between the modified and unmodified blends.

Figure 4 gives a plot of cure time versus reclaim loading. The blends containing modified WTR show higher cure time in all the cure ratios. This may be attributed to the fact that the grafting introduces anhydride group on to the WTR and anhydrides are known cure retarders. The anhydride not only delay onset of cure reaction they also reduces the cure resulting in hither cure times. The observed scorch times and cure rates

\section{Table 3 Cross-link density measurement}

Cross link density in $\mathrm{m}$. mole $/ \mathrm{Kg}$ of rubber hydrocarbon

\begin{tabular}{|c|c|}
\hline Unmodified mix C & Modified mix H \\
\hline 23 & 26 \\
\hline
\end{tabular}

Figure 4 Comparison of cure time with reclaim loading

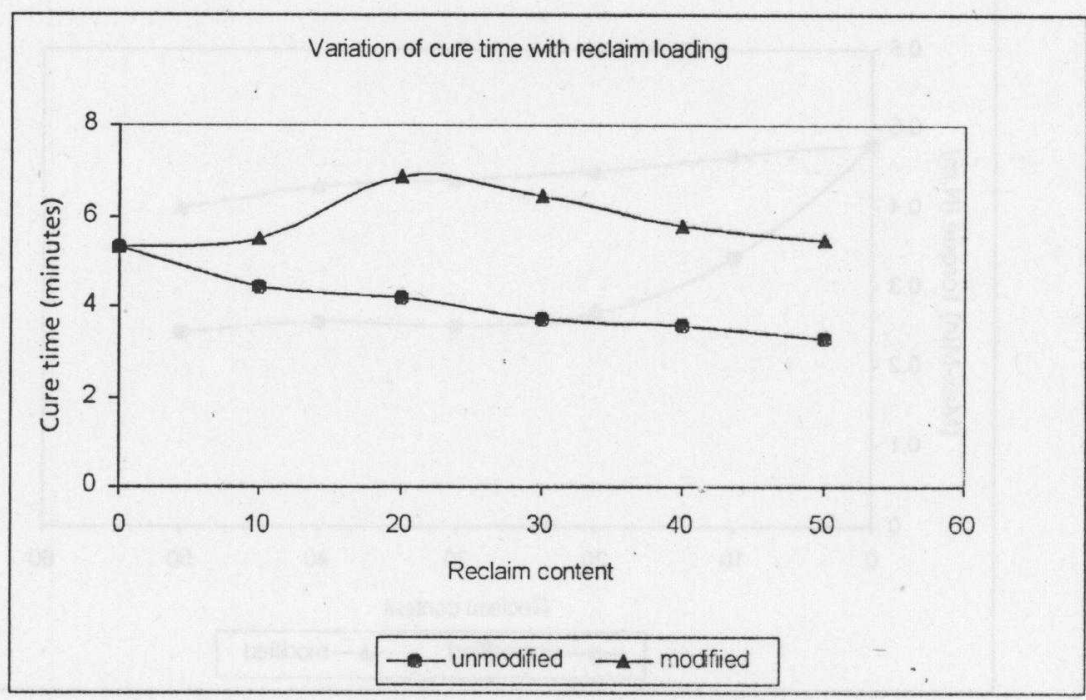


Studies on Maleic Anhydride Grafted Reclaimed Rubber/Acrylonitrile Butadiene Rubber Blends

(Figures 5 and 6) are in agreement with this view. In all the cases the variation with increasing reclaim loading is similar to the blends containing
unmodified WTR.

Figure 5 Comparison of scorch time with reclaim loading

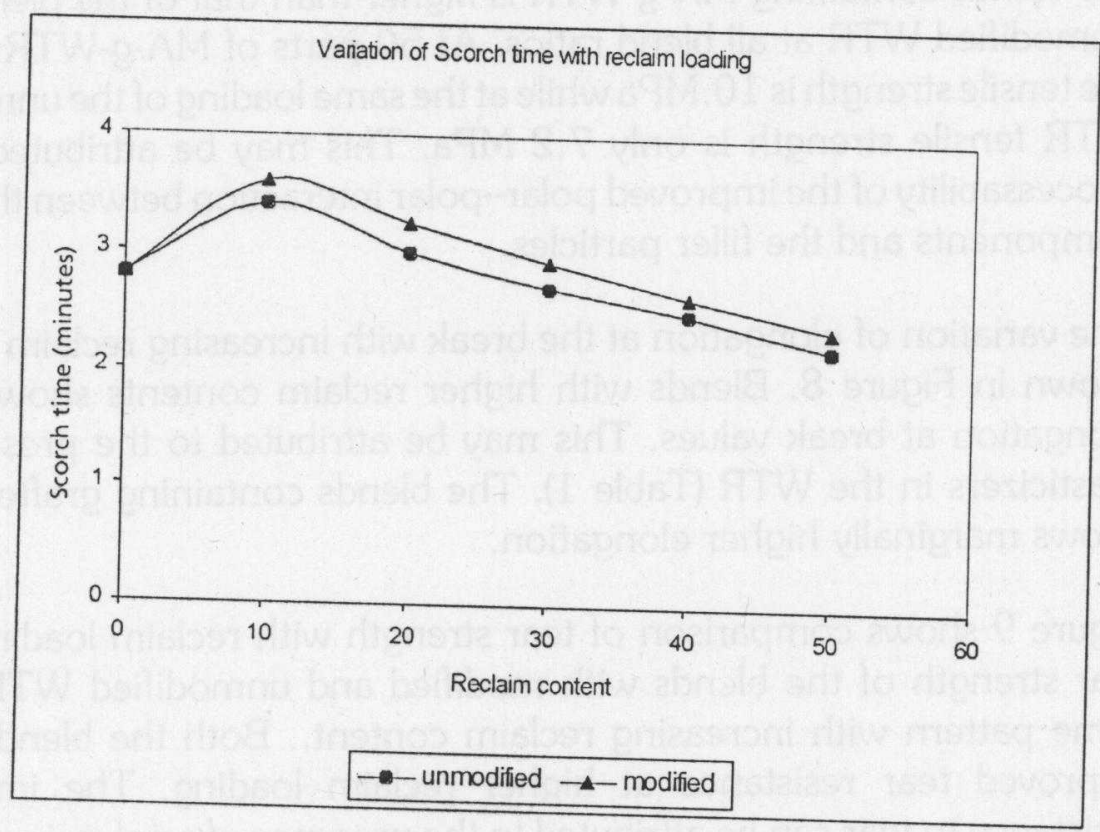

Figure 6 Comparison of cure rate with reclaim loading

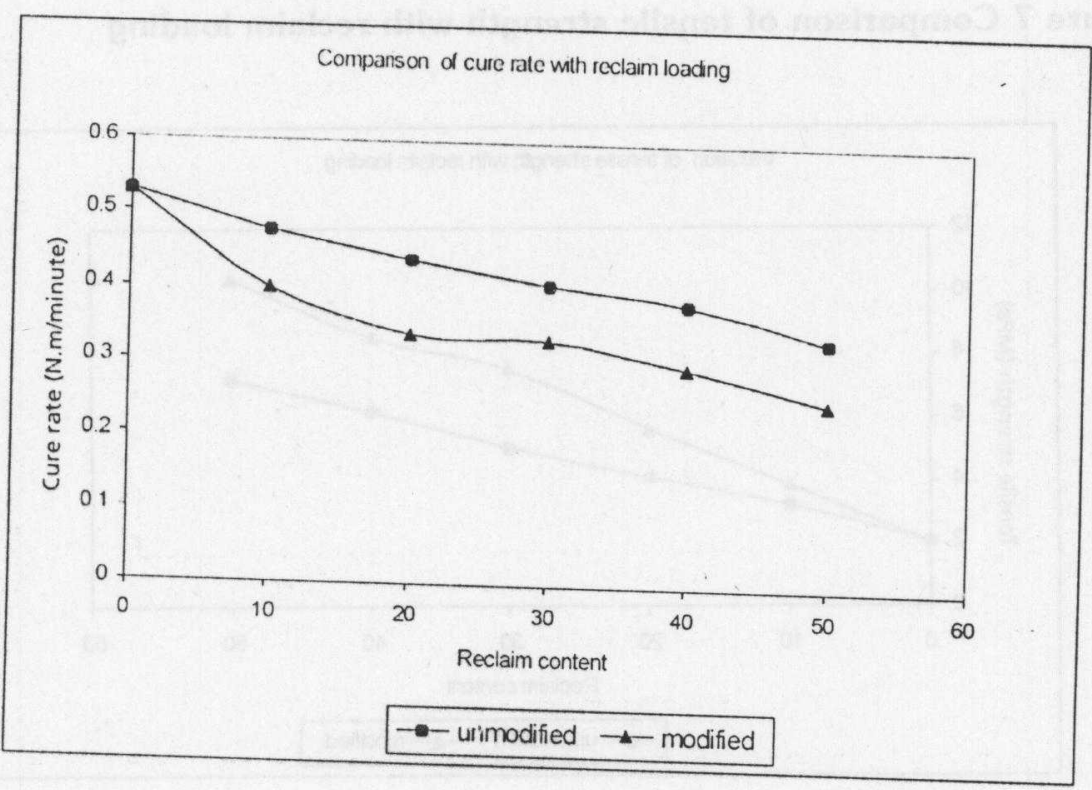




\section{Mechanical properties}

Figure 7 shows the tensile strength of mixes A-K. In all the cases the tensile strength increases with reclaim content. This may be attributed to the reinforcing fillers present in the WTR. Similar results in the case of NR,NBR and BR has been reported earlier ${ }^{(14-16)}$. The tensile strength of the blends containing MA-g-WTR is higher than that of the blends with unmodified WTR at all blend ratios. At 50 parts of MA-g-WTR loading the tensile strength is $10 . \mathrm{MPa}$ while at the same loading of the unmodified WTR tensile strength is only $7.2 \mathrm{MPa}$. This may be attributed to the processability of the improved polar-polar interaction between the blend components and the filler particles.

The variation of elongation at the break with increasing reclaim loading shown in Figure 8. Blends with higher reclaim contents show higher elongation at break values. This may be attributed to the presence of plasticizers in the WTR (Table 1). The blends containing grafted WTR shows marginally higher elongation.

Figure 9 shows comparison of tear strength with reclaim loading. The tear strength of the blends with modified and unmodified WTR show same pattern with increasing reclaim content.. Both the blends show improved tear resistance at higher reclaim loading. The improved resistance to tear can be attributed to the presence of reinforcing filler in the WTR matrix. However, the grafting of the WTR does not seem to have significant effect on the tear strength of the blends.

Figure 7 Comparison of tensile strength with reclaim loading

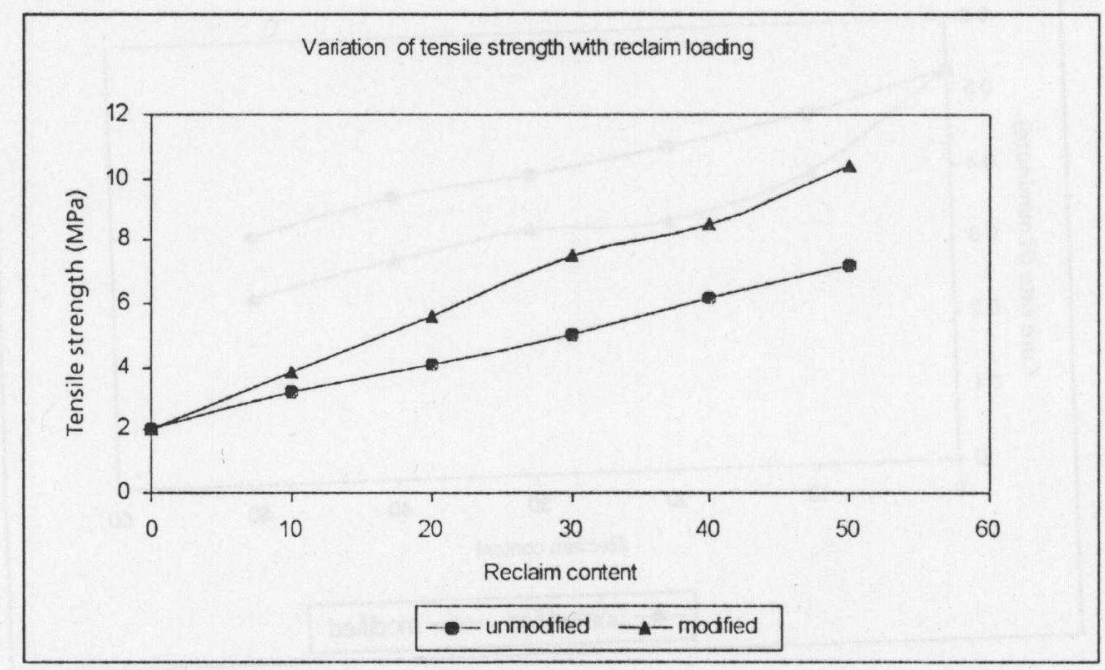


Studies on Maleic Anhydride Grafted Reclaimed Rubber/Acrylonitrile Butadiene Rubber Blends

Figure 8 Comparison of ultimate elongation with reclaim loading

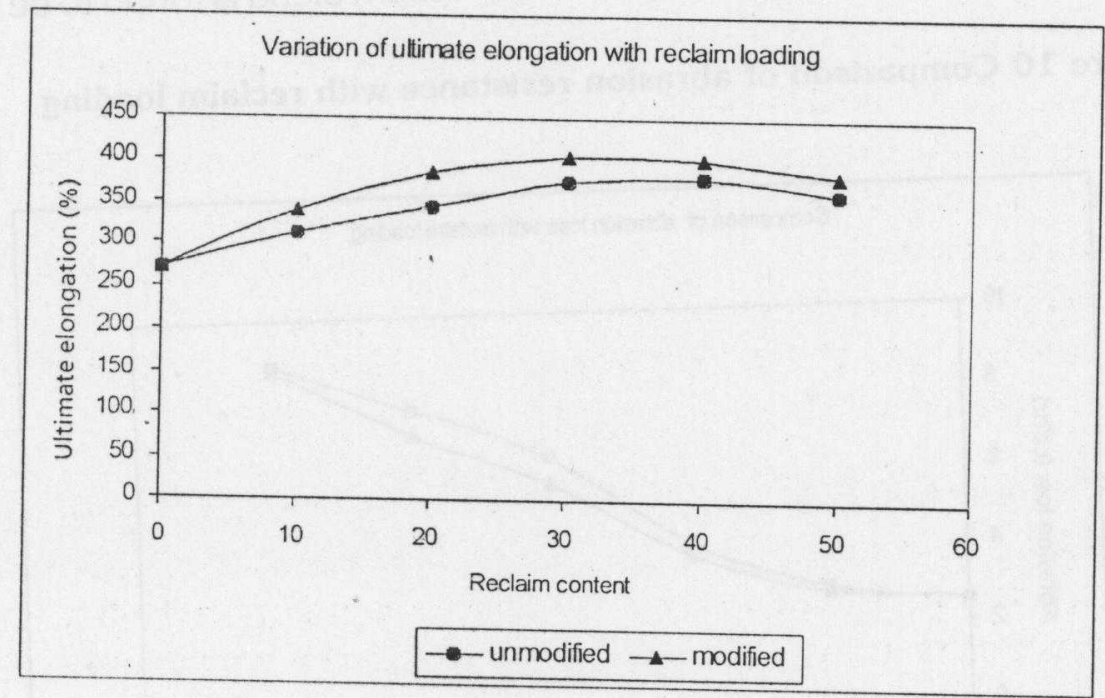

Figure 9 Comparison of tear resistance with reclaim loading

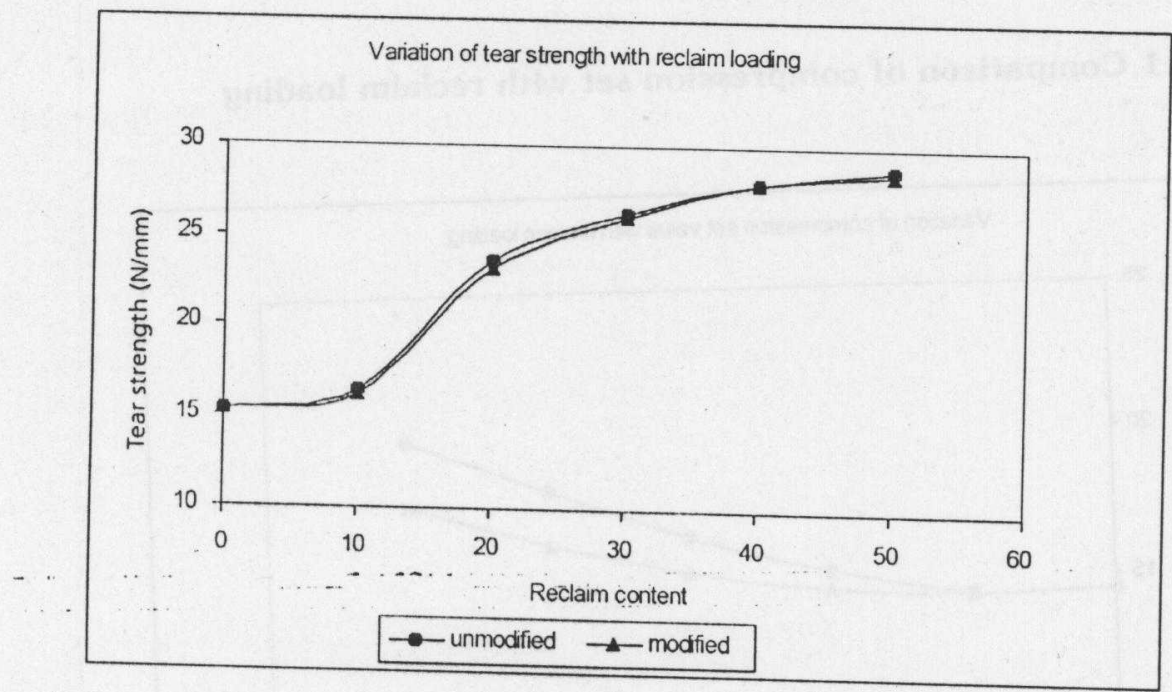

Figure 10 shows a plot of abrasion loss versus reclaim loading. Modified reclaim blend shows a low abrasion loss and hence better abrasion resistance than the unmodified reclaim blend. The low abrasion loss in the case of modified blend can be explained as due to the improved matrix- 
matrix and matrix-filler interaction. A better interface interaction restrains the matrix better, resulting in better abrasion resistance.

Figure 11 shows the comparison of compression set with reclaim loading. Compression set values of the modified reclaim blend is found to be lower

\section{Figure 10 Comparison of abrasion resistance with reclaim loading}

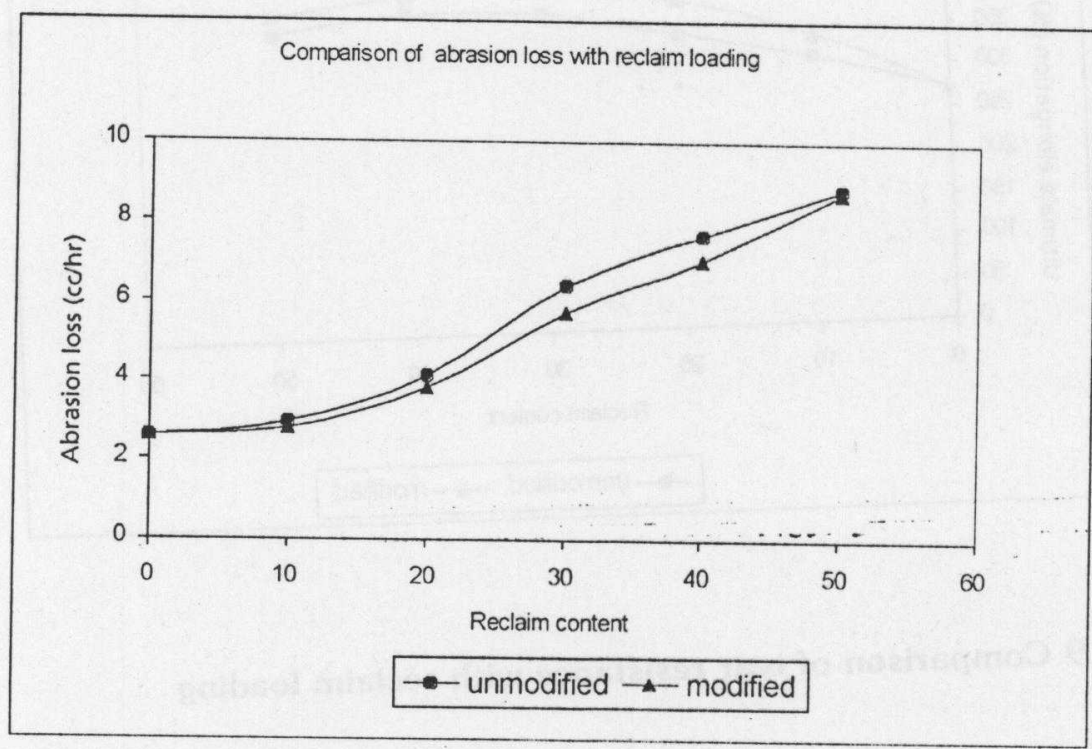

Figure 11 Comparison of compression set with reclaim loading

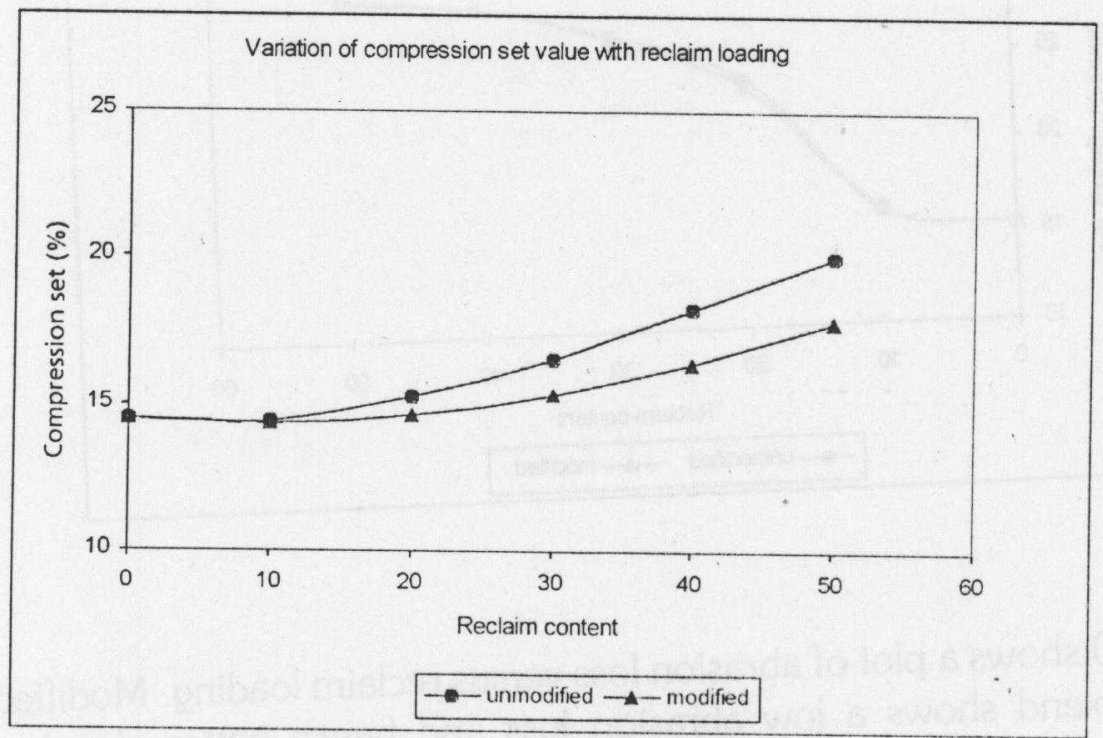


Studies on Maleic Anhydride Grafted Reclaimed Rubber/Acrylonitrile Butadiene Rubber Blends than the unmodified reclaim blend. The reduced compression set values indicates a more restrained matrix. This also supports the view that the grafting improves the interaction between the blend components. The increased set values at higher reclaim loading may be resulting from combined effect of filler, plasticizer and elevated temperature, all of which reduce the elasticity of the matrix. Low elastic matrices facilitate irreversible flow under stress, resulting in higher set values.

The increased elasticity is also evident from Figure 12, which is a plot of resilience values of modified and unmodified reclaim blends versus reclaim loading. The resilience of the modified blend increases with reclaim loading in contrast to the blends containing unmodified blends where the resilience is lower at higher reclaim loading. The apparent difference may be attributed to the better reinforcing effect of the fillers through the improved polar interactions in the case of modified blends. The matrix undergoes relatively more elastics deformation under low strains as a consequence to better reinforcement of the matrix. In the case of the unmodified blends, there is more chance of energy dissipation at filler-matrix interface due to the relatively weak interfacial bonds.

Figure 13 shows comparison of heat build up with the modified and unmodified reclaim loading. The heat generation under dynamic loading

Figure 12 Comparison of resilience with reclaim loading

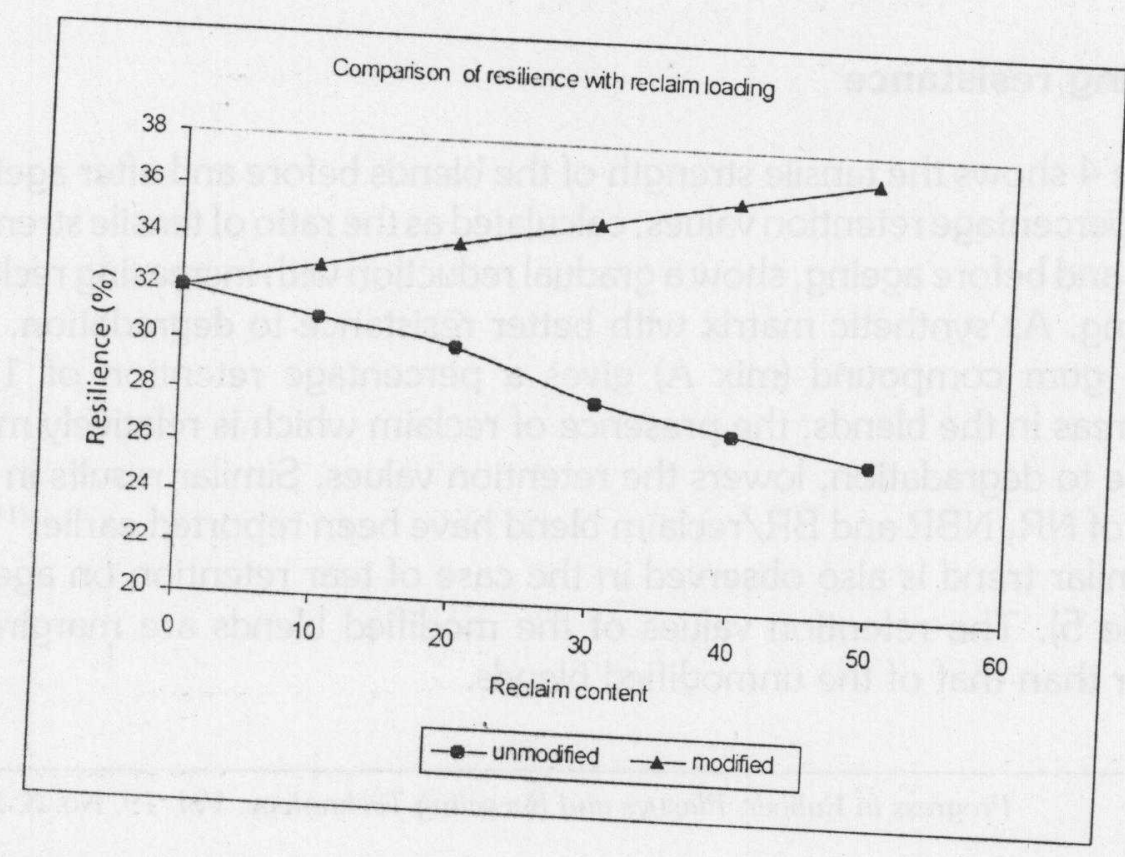


Figure 13 Comparison of heat build up with reclaim loading

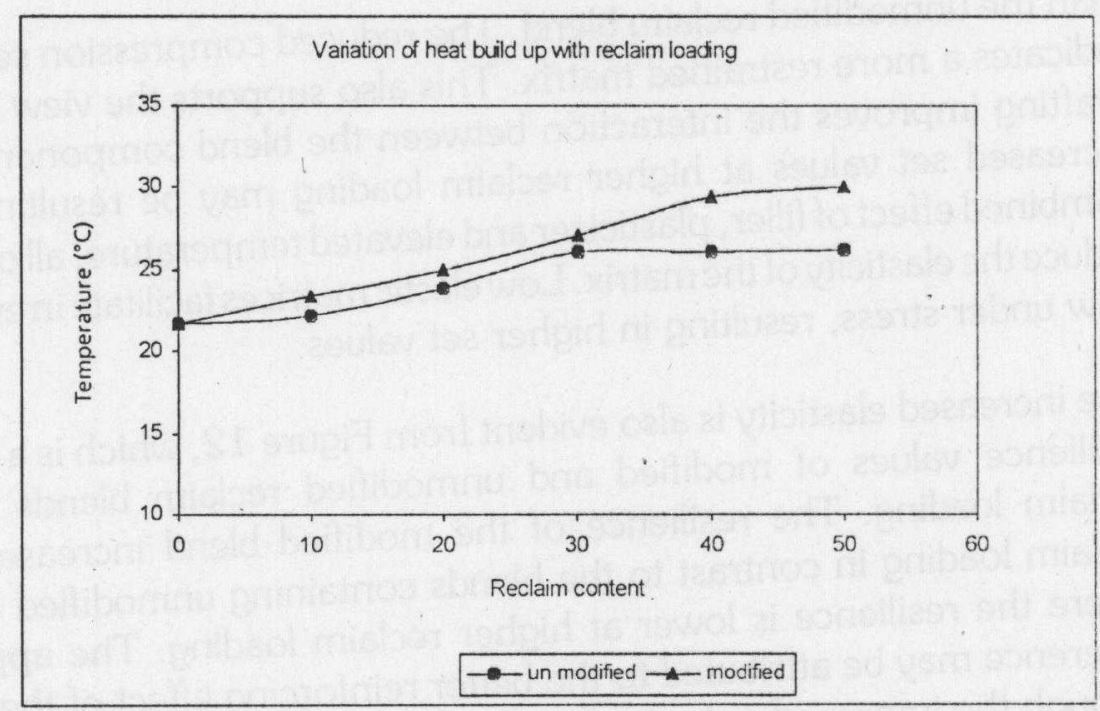

is higher at higher reclaim loading in the case of modified and unmodified blends. The modified blends show higher hysteresis loss, at higher reclaim loading. This is in contrast to the observed resilience values. The difference can mainly be attributed to the difference in the level of strains. In the heat build up test, the samples is strained to a larger extent than in the case of the resilience test. At higher strains, the chance of the energy loss by interfacial bond breakage is more and hence the higher heat generation.

\section{Ageing resistance}

Table 4 shows the tensile strength of the blends before and after ageing. The percentage retention values, calculated as the ratio of tensile strength after and before ageing, show a gradual reduction with increasing reclaim loading. As synthetic matrix with better resistance to degradation, the NBR gum compound (mix A) gives a percentage retention of 120 . Whereas in the blends, the presence of reclaim which is relatively more prone to degradation, lowers the retention values. Similar results in the case of NR, NBR and BR/reclaim blend have been reported earlier(14-16). A similar trend is also observed in the case of tear retention on ageing (Table 5). The retention values of the modified blends are marginally lower than that of the unmodified blends. 
Studies on Maleic Anhydride Grafted Reclaimed Rubber/Acrylonitrile Butadiene Rubber Blends

\begin{tabular}{|c|c|c|c|c|c|c|}
\hline \multicolumn{6}{|c|}{ Table 4 Tensile strength of mixes before and after the ageing } \\
\hline \multirow{2}{*}{$\begin{array}{c}\text { Mix } \\
\text { No. }\end{array}$} & \multicolumn{3}{|c|}{ Tensile strength in MPa } & \multirow{2}{*}{ Percentage retention } \\
\cline { 2 - 7 } & Before ageing & After ageing & \\
\cline { 2 - 7 } & Unmodified $^{*}$ & Modified & Unmodified & Modified & Unmodified & Modified \\
\hline A & - & 2.00 & - & 2.40 & - & 120 \\
\hline B & 3.25 & 3.83 & 3.54 & 3.35 & 109 & 88 \\
\hline C & 4.08 & 5.64 & 4.31 & 5.49 & 106 & 97 \\
\hline D & 5.05 & 7.49 & 5.67 & 7.15 & 112 & 96 \\
\hline E & 6.18 & 8.50 & 6.82 & 8.49 & 110 & 100 \\
\hline F & 7.21 & 10.43 & 8.01 & 10.35 & 111 & 99 \\
\hline * Corresponds to mixes $G, H, I, J$ and $K$ \\
\hline
\end{tabular}

\begin{tabular}{|c|c|c|c|c|c|c|}
\hline \multicolumn{6}{|c|}{ Table 5 Tear resistance of mixes before and after the ageing } \\
\hline \multirow{2}{*}{$\begin{array}{c}\text { Mix } \\
\text { No. }\end{array}$} & \multicolumn{3}{|c|}{ Tear resistance (N/mm) } & \multicolumn{2}{l|}{ Percentage retention } \\
\cline { 2 - 7 } & Before ageing & After ageing & \multicolumn{1}{l|}{} \\
\cline { 2 - 6 } & Unmodified & Modified & Unmodified $^{*}$ & Modified & Unmodified & Modified \\
\hline A & - & 15.19 & - & 15.19 & - & 100 \\
\hline B & 16.38 & 16.00 & 16.16 & 15.83 & 97 & 97 \\
\hline C & 23.61 & 23.15 & 23.17 & 21.16 & 98 & 91 \\
\hline D & 25.25 & 25.09 & 25.35 & 25.19 & 99 & 92 \\
\hline E & 28.03 & -27.92 & 27.62 & 25.02 & 98 & 90 \\
\hline F & 29.74 & 29.56 & 27.56 & 24.61 & 99 & 83 \\
\hline * Corresponds to mixes $G, H, I, J$ and $K$ \\
\hline
\end{tabular}

Table 5 shows the retention values of ultimate elongation of the modified and unmodified sample. Ultimate elongation values of the aged sample are lower than that of the unaged sample (Table 6). Percentage retention values of the modified reclaim blend are again marginally less than the unmodified reclaim blend. 
P.A. Nelson and S.K.N. Kutty

\begin{tabular}{|c|c|c|c|c|c|c|}
\hline \multicolumn{6}{|c|}{ Table 6 Ultimate elongation of mixes before and after the ageing } \\
\hline \multirow{2}{*}{$\begin{array}{c}\text { Mix } \\
\text { No. }\end{array}$} & \multicolumn{3}{|c|}{ Ultimate elongation } & \multicolumn{2}{|c|}{ Percentage retention } \\
\cline { 2 - 6 } & Eefore ageing & After ageing & \\
\cline { 2 - 6 } & Unmodified & Modified & Unmodified $^{*}$ & Modified & Unmodified & Modified \\
\hline A & - & 272 & - & 271 & - & 100 \\
\hline B & 313 & 339 & 308 & 291 & 98 & 86 \\
\hline C & 333 & 386 & 322 & 339 & 97 & 88 \\
\hline D & 377 & 407 & 352 & 345 & 93 & 85 \\
\hline E & 382 & 404 & 362 & 349 & 95 & 86 \\
\hline F & 363 & 392 & 355 & 368 & 98 & 94 \\
\hline * Corresponds to mixes $G, H, I, J$ and $K$ \\
\hline
\end{tabular}

\section{CONCLUSIONS ... .}

Cure characteristics such as minimum torque, (maximum - minimum) torque, scorch time, cure time and cure rate of the nitrile rubber/WTR blend were affected by grafting of maleic anhydride on WTR. While minimum torque, (max-min) torque, cure time, scorch time, were increased with the reclaim loading, cure rate and compression set value at constant strain, were decreased. Heat build up was higher for blends containing modified reclaim. The tensile strength and ultimate elongation were improved; tear strength was unaffected by maleic anhydride grafting. While resilience and abrasion resistance were increased with the maleic anhydride grafting, the ageing resistance of the modified blends was inferior to that of unmodified compound.

\section{REFERENCE}

1. N.R. Barton and J.A. Koutsky, Chem. Eng. News, 52(6), 21(1974)

2. N.R. Barton, Waste age, 61 (May - June 1972) Waste age

3. A.A. Harshaft, Environ. Sci. Technol., 6(5), 412 (1942)

4. A. Ratcliffe, Chem. Eng., 79(7), 62(1972)

5. T.C.P. Lee and W. Millns, US Patent 4,046,834 (1977) (to Gould Inc.) 
Studies on Maleic Anhydride Grafted Reclaimed Rubber/Acrylonitrile Butadiene Rubber Blends

6. M.W. Binchulph, Conserv. Recycl. 1, 169 (1977)

7. D.J. Zolin, N.B. Frable and J.F. Gentlecore, in Meeting of Rubber Division, A.C.S. 1977; Rubber. Chem. Technol., 51, 385 (1978)

8. L.E. Peterson, J.T. Moriarty and W.C. Bryant in Meeting of Rubber Division, A.C.S.1977; Rubber. Chem. Technol., 51, 386 (1978)

9. M.C. Kazanowicz, E.C. Osmundson, J.F. Boyle and R.W. Savage in Meeting of Rubber Division. A.C.S.1977; Rubber. Chem. Technol., 10. J.A. Backman, G. Grane, E.L. Kay and J.R. Laman, Rubber Age,
104(4), 43(1973)

11. G. Crane and E.L. Kay, Rubber. Chem. Technol., 48, 50, (1975)

12. N.P. Chopey, Chem. Eng., 80(20), 54(1973)

13. R.H. Wolk, Rubber Age, 104, 103 (1972)

14. K.F. Kelly, V.G. Nickoleski, V.N. Baleberine, N. Benham, I. Morris and B.M. Kelly, Paper 98 ibid.

15. Sreeja and S.K.N. Kutty, Polym. Plast. Technol. Eng. 39(3), (2000) 501

16. Sreeja and S.K.N. Kutty, Journal of Elastomers and Plastics Volume 34, (2) April 2002 145-155

17. P.A. Nelson and S.K.N. Kutty, Progress in Rubber, Plastics and Recycling Technology, Vol. 18, No.2, 2002

18. J.K. Kim and R.B. Burford, "Studies on powder utilization of waste tires as a filler in rubber compounding", Rubber Chem. Tech., 71,
$5,1028,1998$

19. E.H. Farmer and J.U.S. Wheeler, Patent 2,227,777 (to British Rubber Products)

20. D.F. Lawson, W.L. Hergenrother and M.G. Matlock, J. Appl Polymer. Sci., 39, 2331(1990)

21. B.C. Trivediand B.M. Culberton, Maleic Anhydride, Plenum, pp.172-
3 New York (1982)

22. B. Ellis and P.M Sanderson, J. Chemical Society., 3240 (1972)

23. Ibid., Rubber Chem. Techno., 37, 571(1964)

24. P.J. Florey and J. Rehner, J. Chem. Phys, 11, 512(1943) 
P.A. Nelson and S.K.N. Kutty

25. P.J. Florey, J. Chem. Phy., 18, 108 (1950)

26. C.J. Sheelan and A.L. Basolo, Rubber, Rubber Chem. Technol. 39 , 144 (1966) 